\title{
Comparative survey on using two passive cooling systems, solar chimney- earth to air heat exchanger and solar chimney-evaporative cooling cavity
}

\author{
Amin Haghighi Poshtiri ${ }^{1, *}$, Neda Gilani ${ }^{2}$, Farshad Zamiri ${ }^{3}$ \\ ${ }^{1}$ Guilan University, Rasht, Iran \\ ${ }^{2}$ Tarbiat modares University, Tehran, Iran \\ ${ }^{3}$ Mapna Company, Tehran, Iran \\ *Corresponding author. Tel: +98 1316690273, Fax: +98 1316690271,E-mail: aminhaghighi_p@yahoo.com
}

\begin{abstract}
In this study using two low-energy systems to enhance passive cooling and natural ventilation in a solar room have been compared. First system consists of a Solar Chimney (SC) and an Evaporative Cooling Cavity (ECC) and the second one includes a Solar Chimney (SC) and an Earth-to-Air Heat exchanger (EAHE). To determine the heat and mass transfer characteristics of the systems, a mathematical model based on conservation equations of mass and energy has been developed and solved by an iterative method. The findings show that when the cooling demand of the room is $116 \mathrm{~W}$ and the relative humidity is lower than $50 \%$, the SCECC system can make acceptable indoor air conditioning even at ambient $40^{\circ} \mathrm{C}$, with weak solar intensity of 200 $\mathrm{W} / \mathrm{m}^{2}$. It is also found that, the proposed system can provide thermal comfort conditions even during the night with zero solar radiation. The results about SC-EAHE system show that when the ambient temperature and cooling demand are high $(1500 \mathrm{~W})$, proper configurations could provide good indoor condition even at poor solar intensity of $100 \mathrm{~W} / \mathrm{m}^{2}$ and high ambient air temperature of $50^{\circ} \mathrm{C}$. Comparative survey shows the SC-EAHE system is the best choice for buildings with poor insulation at day time, but SC-ECC system is better for night ventilation and cooling purposes especially in arid climates.
\end{abstract}

Keywords: Comparative survey, Passive cooling, SC-EAHE, SC-ECC.

\section{Nomenclature}

A area $m^{2}$

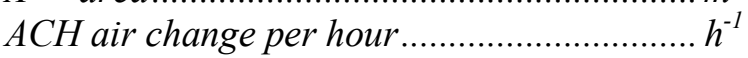

$b \quad$ width of cooling cavity..........................m

C specific heat of air ........................ $/ \mathrm{kgK}$

$c$ pressure loss coefficient of fittings ............ -

$d \quad$ air gap depth, diameter .......................... $m$

$f \quad$ wettability percent ................................. \%

fre frequency of temperature oscillation.. $\mathrm{rad} / \mathrm{s}$

g gravitational constant...................... $\mathrm{m} / \mathrm{s}^{2}$

$H$ distance............................................... $m$

$h$ convective heat transfer coefficient $W / m^{2} . K$

$h r$ radiative heat transfer coefficient... W/m $\mathrm{m}^{2} . K$

$k \quad$ thermal conductivity......................W/m.K

$L \quad$ length ............................................ $m$

$m$ mass flow rate of air ....................... kg/s

$Q \quad$ heat transfer to air stream .................W/ $\mathrm{m}^{2}$

$R$ thermal resistance.......................... $m^{2} . K / W$

$R H$ relative humidity.................................. $\%$

$r \quad$ radius..................................................... $m$

$S \quad$ solar radiation absorbed by plate....... W/ $/ \mathrm{m}^{2}$

$T$ temperature...........................................

$t \quad$ thickness..............................................m

$U$ overall heat transfer coefficient...... W/ $\mathrm{m}^{2} . \mathrm{K}$

$u \quad$ air velocity ........................................ $\mathrm{m} / \mathrm{s}$

$V \quad$ volume of room ................................. $\mathrm{m}^{3}$ $x \quad$ coordinate system ...............................m

\begin{tabular}{|c|c|}
\hline & ek symbols \\
\hline$\gamma$ & constant in Eq.(2) ......... \\
\hline$\delta$ & heat penetration depth....... \\
\hline$\lambda$ & thermal diffusivity............................ $\mathrm{m}^{2} / \mathrm{s}$ \\
\hline$\xi$ & friction factor ......................................... \\
\hline$\rho$ & $\ldots \ldots \ldots \ldots \ldots \ldots \ldots . . . k g / m^{3}$ \\
\hline$\omega$ & humidity ratio..... \\
\hline
\end{tabular}

\section{Subscripts}

a ambient...

abs absorber wall.

cc cooling cavity

$f$ airflow

$g$ glass...

hyd hydraulic.

$i$ internal...

in inlet.

$r$ room

su undisturbed soil.

$s$ soil.

$t$ pipe

o outlet.

w water. 


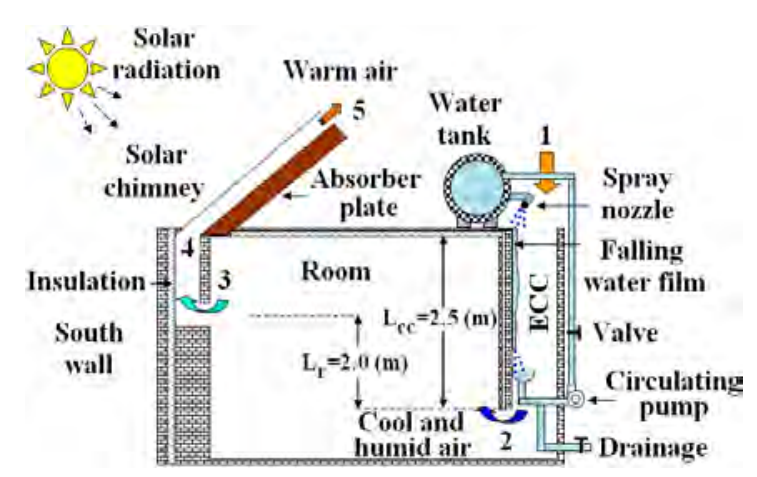

Fig. 1. Schematic diagram of SC-ECC system.

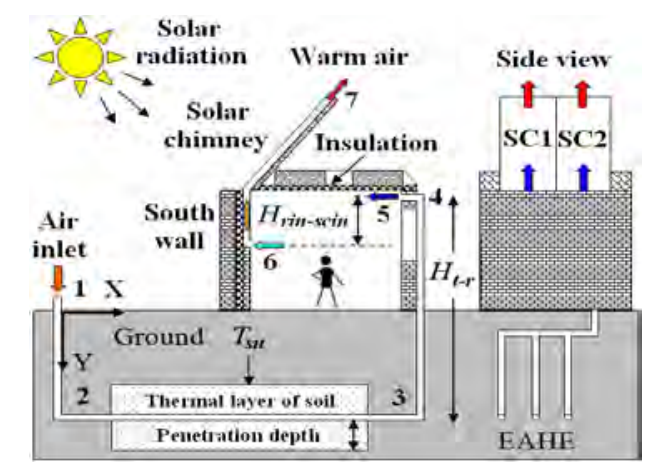

Fig. 2. Schematic diagram of SC-EAHE system.

\section{Introduction}

In order to reduce global warming and to reduce electricity peak demands during summer time low or zero energy cooling systems are required. passive cooling applications shall offer great advantage and it is growing at an increasing rate worldwide. These systems had attracted much attention of investigators and researchers. Giabaklou and Ballinger [1] presented a method of passive cooling in low-rise multi-storey buildings through a simple water cascade associated with openings and balconies of individual. This system applies the evaporative cooling technique to reduce ambient air temperature by passing air over the water falling film. Manzan and Saro [2] studied a system consisting of a ventilated roof with a wet lower surface of the cavity which flows the external air. They investigated thermal performance of the system by numerical modeling of evaporative cooling process through the chimney. Dai et al. [3] presented a new passive cooling system for humid climate using the solar chimney and adsorption cooling system. They showed that the system increases the rate of ventilation and provides the cooling without increasing humidity of the room. Chungloo and Limmeechokchai [4] experimentally investigated the performance of a system consisting of a solar chimney and water spraying system that was placed on the roof under hot and humid climate. They reported that the system performed well in high ambient temperature. Maerefat and Haghighi [5] presented another technique, using a system consisting of a SC and an ECC. The capability of the system to meet the required thermal needs of individuals, the effects of main geometric parameters on the system performance and the dependence of the system performance on outdoor air temperature was also studied. Maerefat and Haghighi [6] introduced and investigated integrated EAHE-SC system. They showed that the SC can be perfectly used to power the underground cooling system during the daytime, without any need for electricity.

Here, using SC-ECC and SC-EAHE systems to enhance passive cooling and natural ventilation in a solar room have been compared together. Figs. 1 and 2 illustrates a schematic plan of the two systems. The SC consists of a glass-made surface faced to the south and an absorber wall. EAHE consists of horizontal long pipe placed underground. The air gets warmed in SC, and by natural convection mechanism, the outside air is sucked-in through the pipe or ECC. It will be shown that these systems can provide good indoor condition in accordance with the Adapted Comfort Standard (ACS) (Fig. 3). ACS does not recommend the ventilation rate. Therefore, the minimum ventilation rate is set around $3 \mathrm{ACH}$ [7].

\section{Problem formulation}

The modeling includes models of SC (Fig. 4), ECC (Fig. 5) and EAHE (Fig. 6). The following assumptions are made in this analysis.

1. The air temperature at the room is uniform. 


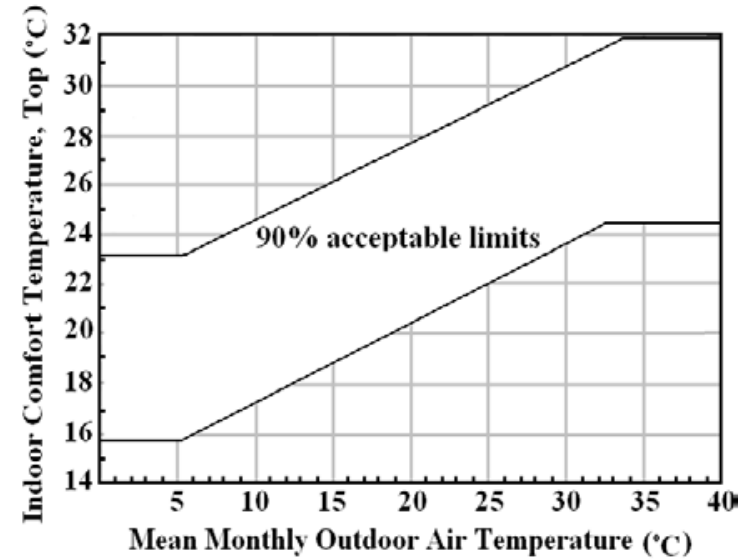

Fig. 3. Adaptive Comfort standard.

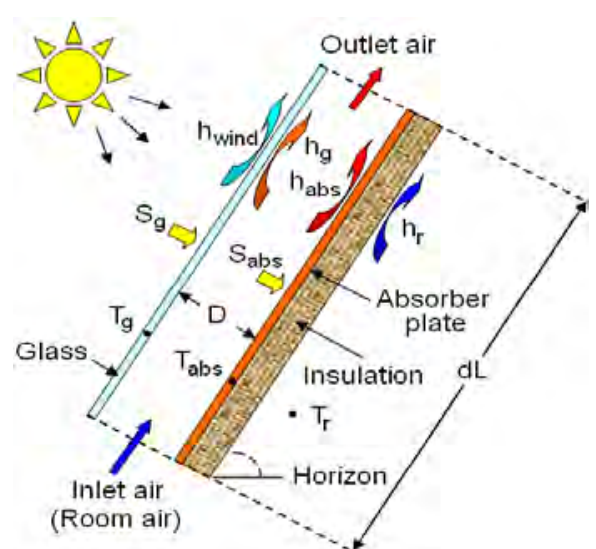

Fig. 4. Diagram of the heat transfer in the SC.

2. Only buoyancy force is considered and wind induced natural ventilation is not included.

3. The flows in the channels are laminar and hydro dynamically and thermally fully developed.

4. The glass cover is opaque for infrared radiation.

5. Thermal capacities of glass and wall are negligible.

6. The air flow in the channel is radiative non-participating medium.

7. The soil is homogeneous and the soil type does not change along the channel.

8. Thermal resistance of water film is negligible.

9. The spray enthalpy is negligible.

10. The air enthalpy is expressed as linear function of wet bulb temperature.

11. The Lewis number correlating heat and mass transfer is 1.0.

12. All thermo physical properties are all evaluated at average temperature.

13. The system is at steady-state condition.

\subsection{Mathematical modeling of SC-ECC}

An element of the model for SC is shown in Fig. 4. In principle and based on the energy conservation law, a set of differential equations are obtained along the length of SC [5].

$$
\begin{aligned}
& S_{g} A_{g}+h r_{a b s-g} A_{a b s}\left(T_{a b s}-T_{g}\right)=h_{g} A_{g}\left(T_{g}-T_{f s c}\right)+U_{g-a} A_{g}\left(T_{g}-T_{f s c}\right) \\
& h_{a b s} A_{a b s}\left(T_{a b s}-T_{f s c}\right)+h_{g} A_{g}\left(T_{g}-T_{f s c}\right)=-m C_{f s c}\left(T_{f s c}-T_{r}\right) / \gamma \\
& S_{a b s} A_{a b s}=h_{a b s} A_{a b s}\left(T_{a b s}-T_{f s c}\right)+h r_{a b s-g} A_{a b s}\left(T_{a b s}-T_{g}\right)+U_{a b s-a} A_{a b s}\left(T_{a b s}-T_{a}\right)
\end{aligned}
$$

All of coefficients and the overall heat transfer coefficients are obtained from Ref. [5].

An element of the model for ECC is shown in Fig. 5. For the energy and mass conservation law a set of differential equations are to be considered along the length of the cooling cavity.

$$
\begin{aligned}
& \frac{d \omega_{f c c}}{d x}=-h_{m} f b\left(\omega_{f c c\left(T_{w}\right)}-\omega_{f c c}\right) / m \\
& \frac{d T_{f c c}}{d x}=\frac{b h_{f c c} f\left(T_{w}-T_{f c c}\right)}{m C_{f c c}}+\frac{H_{f c c\left(T_{w}\right)}-H_{f c c}}{C_{f c c}} \frac{d \omega_{f c c}}{d x}+\frac{b U_{a-f c c}\left(T_{a}-T_{f c c}\right)}{m C_{f c c}} \\
& \frac{d T_{w}}{d x}=\left[m \frac{d H_{f c c}}{d x}+b\left(U_{r-w} f\left(T_{r}-T_{w}\right)-m C_{p w} T_{w} \frac{d \omega_{f c c}}{d x}\right)\right] / m_{w} C_{p w}
\end{aligned}
$$

The required boundary conditions for solving Eq. 4-6 in a cocurrent type air flow configuration are: 


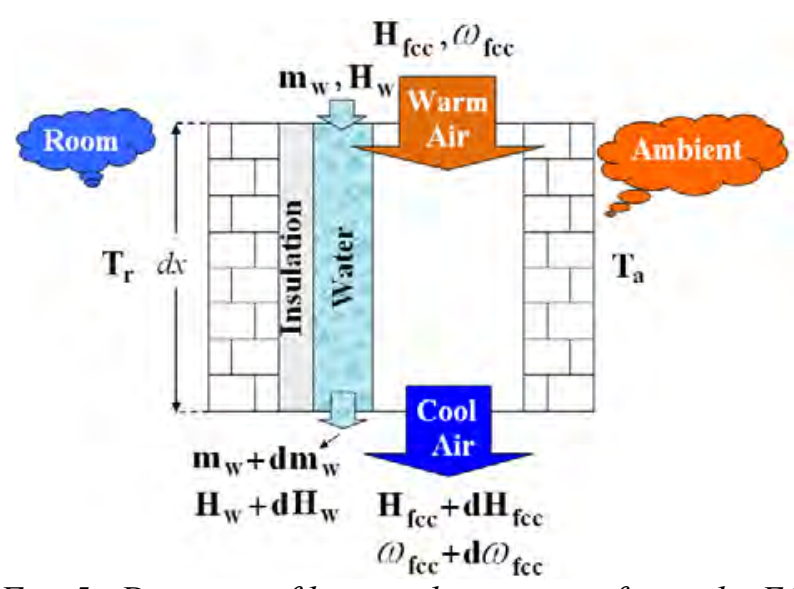

Fig. 5. Diagram of heat and mass transfer in the ECC.

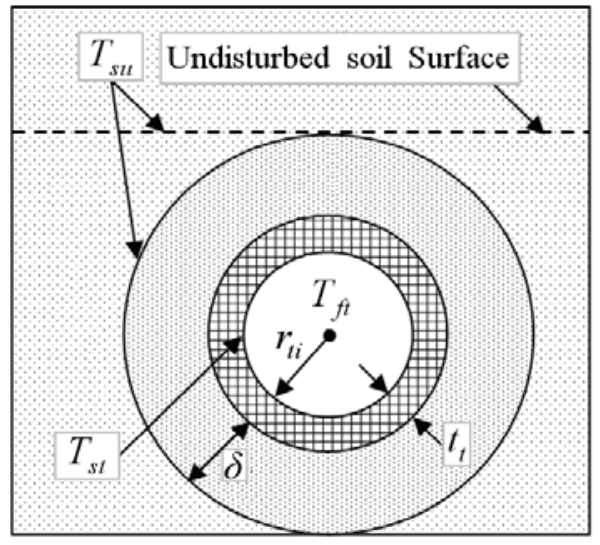

Fig. 6. Cross section of an EAHE.

$T_{f c c}(0.0)=T_{a}, T_{w}(L)=T_{w}(0.0)$

$R H_{f c c}(0.0)=R H_{a}$

A mathematical model based on Bernoulli's equation is used to estimate the system flow rate. The air velocity in the SC can be obtained as [5]:

$u_{f s c}=\sqrt{\frac{\text { Bouyancy Terms }}{\text { Friction Terms }}}$

Bouyancy Terms $=2\left\{\left(\rho_{f a}-\rho_{f s c o}\right) g L_{s c} \operatorname{Sin}(\theta)-\left(\rho_{f c c o}-\rho_{f r}\right) g L_{r}+\left(\rho_{f c c o}-\rho_{f a}\right) g L_{c c}\right\}$

Friction Terms $=\left\{c_{5}+\xi_{s c} \frac{L_{s c}}{\left(d_{h y d}\right)}\right\} \rho_{s c}+c_{4}\left(\frac{\rho_{f s c o} A_{s c o}}{\rho_{r} A_{s c o}}\right)^{2} \rho_{f r}+c_{3}\left(\frac{\rho_{\text {fsco }} A_{s c o}}{\rho_{r} A_{s c i n}}\right)^{2} \rho_{f r}$

$$
+c_{2}\left(\frac{\rho_{f s c o} A_{s c o}}{\rho_{f c c o} A_{c c}}\right)^{2} \rho_{f c c o}+c_{1}\left(\frac{\rho_{f s c o} A_{s c o}}{\rho_{f a} A_{c c}}\right)^{2} \rho_{f a}+\xi_{c c} \frac{L_{c c}}{\left(d_{h y d}\right)}\left(\frac{\rho_{f c c} A_{s c o}}{\rho_{f c c o} A_{c c}}\right)^{2} \rho_{f c c}
$$

The coupled governing equations (1)-(3), (4)-(6) and (9) are the full description of the system. The governing equations have to be solved iteratively until convergence of the results.

The ACH is calculated under steady-state conditions by the following equation:

$$
A C H=3600 m /\left(\rho_{f s c} V\right)
$$

The room air temperature which depends on room heat gain $\left(Q_{r}\right)$ is given by:

$T_{r}=T_{f s c o u t}-Q_{r} /\left(m C_{f r}\right)$

\subsection{Mathematical modeling of SC-EAHE}

The cross section of EAHE used in the model is shown in Fig. 6. In order to impose the ground thermal loads as boundary conditions at the EAHE wall, the undisturbed soil temperature $\left(T_{s u}\right)$ has been applied in the equations as well. The soil temperature is nearly constant at the penetration depth. It is defined when the surface of the soil is subject to periodic temperature [6].

$\delta=\sqrt{2 \lambda_{s} / \text { fre }}$

The air temperature through the EAHE is calculated by the following equation [6].

$T_{f t}(x)=T_{s u}+\left(T_{a}-T_{s u}\right) \exp \left(-x /\left(m_{f t} C_{f t} R_{t o t a l}\right)\right)$ 
Where $R_{\text {total }}$ represents the overall thermal resistance and is given by [6]:

Table 1. Thermophysical properties.

\begin{tabular}{lc}
\hline \multicolumn{1}{c}{ Parameter } & Value \\
\hline Absorptivity of the glass & 0.06 \\
Emissivity of the glass & 0.90 \\
Transmissivity of the glass & 0.84 \\
Absorptivity of the absorber wall & 0.95 \\
Emissivity of the absorber wall & 0.95 \\
Thermal conductivity of the break wall & $0.72\left(\mathrm{Wm}^{-1} \mathrm{~K}^{-1}\right)$ \\
Thickness of break wall & $0.10\left(\mathrm{~m}^{-1}\right)$ \\
Thermal conductivity of SC and ECC insulation & $0.16\left(\mathrm{Wm}^{-1} \mathrm{~K}^{-1}\right)$ \\
Thickness of SC and ECC insulation & $0.002\left(\mathrm{~m}^{-1}\right)$ \\
Thermal conductivity of the pipe (PVC) & $0.23\left(\mathrm{Wm}^{-1} \mathrm{~K}^{-1}\right)$ \\
Soil density & $2050\left(\mathrm{~kg} \mathrm{~m}^{-3}\right)$ \\
Thermal conductivity of the Soil & $0.52\left(\mathrm{Wm}^{-1} \mathrm{~K}^{-1}\right)$ \\
Specific heat of soil & $1840\left(\mathrm{~J} \mathrm{~kg}^{-1} \mathrm{~K}^{-1}\right)$ \\
\hline
\end{tabular}

$$
R_{\text {total }}=\frac{1}{2 \pi L_{t}}\left(1 / h_{f t}+\ln \left(\frac{r_{t i}+t_{t}}{r_{t i}}\right) / k_{t}+\ln \left(1+\frac{\delta}{r_{t i}+t_{t}}+\sqrt{\left(1+\frac{\delta}{r_{t i}+t_{t}}\right)^{2}-1}\right) / k_{s}\right)
$$

The air velocity in the SC based on Bernoulli's equation can be obtained by the Eq.9 [6].

$$
\begin{aligned}
& \text { Bouyancy Terms }=2\left\{\begin{array}{l}
\left(\rho_{f a}-\rho_{f s c o}\right) g L_{s c} \operatorname{Sin}(\theta)-\left(\rho_{f s i n}-\rho_{f r}\right) g H_{r i n-s c i n} \\
-\left(\rho_{f t}-\rho_{f r}\right) g H_{t-r}
\end{array}\right\} \\
& \text { Friction Terms }=c_{6}\left(\frac{\rho_{f s c o} A_{s c o}}{\rho_{f r} A_{s c i n}}\right)^{2} \rho_{f r}+\left\{c_{7}+\xi_{s c} \frac{L_{s c}}{\left(d_{h y d}\right)_{s c}}\right\} \rho_{f s c o} \\
& +\left\{\left(\sum_{j=1}^{5} c_{j}+\xi_{t} \frac{L_{t}+H_{t-r}+\text { Burried depth of EAHE }}{d_{t}}\right)\left(\frac{\rho_{\text {fsco }} A_{s c o}}{\rho_{f t} A_{t}}\right)^{2}\right\} \rho_{f t}
\end{aligned}
$$

All of coefficients and the overall heat transfer coefficients are obtained from Ref. [6]. The coupled governing equations have to be solved iteratively until convergence of the results.

\section{Methodology}

Two systems are located in Tehran, having $35.44^{\circ} \mathrm{N}$ latitude position. A south-facing solar chimney with the length of $4.0 \mathrm{~m}$, air gap depth of $0.2 \mathrm{~m}$ and inlet dimensions of $0.4 \times 0.4 \mathrm{~m}$ is assumed for analysis. The outlet dimensions of SC and room are $0.2 \mathrm{~m} \times 1.0 \mathrm{~m}$ and $0.1 \mathrm{~m} \times 4.0$ $\mathrm{m}$ respectively. A detailed study on solar chimney found the optimum angle of $50^{\circ}$ to capture more radiation [5].

The ECC is a Cubic channel with the height of $2.0 \mathrm{~m}$ and $2.0 \mathrm{~m} \times 0.05 \mathrm{~m}$ inside cross section. The wettability percent of wetted wall is 0.7 . The calculations are carried out for a room, having a size of $4.0 \mathrm{~m} \times 4.0 \mathrm{~m} \times 3.125 \mathrm{~m}$ without air infiltration. The ECC outlet is lowered 2.0 $\mathrm{m}$ below the SC inlet (Fig.1). 
The cooling pipe of EAHE is a PVC pipe with $25.0 \mathrm{~m}$ length, $0.002 \mathrm{~m}$ thickness, and inside diameter of $0.5 \mathrm{~m}$ and is buried $3.0 \mathrm{~m}$ below the soil surface. The initial soil temperature at surrounding is approximated to be $19^{\circ} \mathrm{C}$ and it is considered to be the heat source temperature. It should be noted that the SC inlet is lowered $0.5 \mathrm{~m}$ below the EAHE outlet (Fig.2). The cooling demand is assumed to change within the range of $0.0-1000 \mathrm{~W}$ in the calculations.

Table 2. Performance of the SC-ECC system at different indoor and outdoor conditions.

\begin{tabular}{|c|c|c|c|c|c|}
\hline $\begin{array}{c}\text { Cooling } \\
\text { demand (W) }\end{array}$ & $\begin{array}{l}\text { Ambient air } \\
\text { RH. (\%) }\end{array}$ & $\begin{array}{l}\text { Ambient air } \\
\text { temp. }\left({ }^{\circ} \mathrm{C}\right)\end{array}$ & $\begin{array}{c}\text { Solar radiation } \\
\left(\mathrm{W} / \mathrm{m}^{2}\right)\end{array}$ & $\begin{array}{c}\mathrm{ACH} \\
\left(\mathrm{h}^{-1}\right)\end{array}$ & $\begin{array}{l}\text { Room air } \\
\text { temp. }\left({ }^{\circ} \mathrm{C}\right)\end{array}$ \\
\hline \multirow{9}{*}{116} & \multirow{3}{*}{30} & 40 & 100 & 2.12 & 31.18 \\
\hline & & 42 & 500 & 3.76 & 31.34 \\
\hline & & 43 & 900 & 4.76 & 31.92 \\
\hline & \multirow{3}{*}{50} & 40 & 200 & 2.23 & 31.45 \\
\hline & & 41 & 500 & 3.78 & 31.58 \\
\hline & & 42 & 900 & 4.85 & 32.00 \\
\hline & \multirow{3}{*}{70} & 35 & 300 & 3.10 & 31.28 \\
\hline & & 36 & 500 & 3.82 & 31.57 \\
\hline & & 37 & 900 & 4.83 & 31.92 \\
\hline \multirow{9}{*}{500} & \multirow{3}{*}{30} & 34 & 300 & 3.55 & 32.00 \\
\hline & & 35 & 500 & 4.23 & 31.57 \\
\hline & & 37 & 900 & 5.13 & 31.88 \\
\hline & \multirow{3}{*}{50} & 31 & 400 & 4.00 & 31.40 \\
\hline & & 32 & 500 & 4.28 & 31.70 \\
\hline & & 34 & 900 & 5.18 & 32.00 \\
\hline & \multirow{3}{*}{70} & 28 & 400 & 4.00 & 31.35 \\
\hline & & 29 & 500 & 4.34 & 31.67 \\
\hline & & 31 & 900 & 5.23 & 32.00 \\
\hline 1000 & \multicolumn{5}{|c|}{ Thermal comfort cannot be provided. } \\
\hline
\end{tabular}

The indoor room air temperature is kept in the thermal comfort range (Fig. 3) to secure the desired condition inside the room space. The ambient air temperature, relative humidity and wind velocity are $34 \mathrm{oC}, 30 \%$ and $1.0 \mathrm{~m} / \mathrm{s}$, respectively. The thermo physical properties of the materials included in the modeling are given in Table 1 . The values of the properties specified in the table are kept constant in the computation unless specifically noted otherwise.

\section{Result and discussion}

\subsection{Effects of environmental conditions on the performance of SC-ECC system}

The influence of solar radiation and humidity on ACH and room air temperature is investigated herein. The ACH depends on the density difference between ambient air and SC outlet air. This difference is more highlighted when the solar radiation rises therefore leading to higher ACH as shown in Table 2. Comparison of the results which are obtained for one SC and ECC shows that the variation of ACH due to the variation of ambient $\mathrm{RH}$ is not significant. However, the applicability of system to provide thermal comfort conditions is reduced at higher ambient air RH. At low ambient air temperatures, good indoor condition can be achieved in a wide range of the ambient air humidity. The results also shows that when ambient R.H. and temperature are less or equal to $50 \%$ and $40^{\circ} \mathrm{C}$, respectively, room air temperature and $\mathrm{ACH}$ would remain in the desired range of thermal comfort. It means that when air temperature rises, thermal comfort can be achieved in lower humidity. It is found that the proposed system can provide thermal comfort conditions even during the night with zero solar radiation (Table 3). It is due to the buoyancy effect in the cooling cavity which can 
draw the cooled air into the room. At night, the chimney effect is non-existant. Therefore, the buoyancy effect of the ECC will be the dominant. Anyhow, to reduce the pressure losses of the air flow during the night, the discharged air may leave the room through an opened window.

Table 3. Performance of the system at zero solar radiation (cocurrent type)

\begin{tabular}{cccccc}
\hline $\begin{array}{c}\text { Cooling } \\
\text { demand }(\mathrm{W})\end{array}$ & $\begin{array}{c}\text { Ambient air } \\
\text { temp. }\left({ }^{\circ} \mathrm{C}\right)\end{array}$ & $\begin{array}{c}\text { Ambient air } \\
\text { RH. }(\%)\end{array}$ & $\begin{array}{c}\text { ACH } \\
\left(\mathrm{h}^{-1}\right)\end{array}$ & $\begin{array}{c}\text { Room air } \\
\text { temp. }\left({ }^{\circ} \mathrm{C}\right)\end{array}$ & $\begin{array}{c}\text { Number of } \\
\text { SC \& ECC }\end{array}$ \\
\hline \multirow{3}{*}{116} & 30 & 50 & 1.71 & 28.80 & 1 \\
& & 70 & 1.63 & 31.77 & 1 \\
& & 30 & 2.21 & 31.72 & 1 \\
& 40 & 50 & \multicolumn{2}{c}{ Thermal } & comfort cannot be provided. \\
& 70 & \multicolumn{4}{c}{ comfort cannot be provided. } \\
\hline
\end{tabular}

Table 4. Performance of the SC-EAHE system at different indoor and outdoor conditions.

\begin{tabular}{|c|c|c|c|c|c|c|}
\hline $\begin{array}{c}\text { Cooling } \\
\text { demand (W) }\end{array}$ & $\begin{array}{l}\text { Ambient air } \\
\text { temp. }\left({ }^{\circ} \mathrm{C}\right)\end{array}$ & $\begin{array}{c}\text { Solar radiation } \\
\left(\mathrm{W} / \mathrm{m}^{2}\right)\end{array}$ & $\begin{array}{l}\mathrm{ACH} \\
\left(\mathrm{h}^{-1}\right)\end{array}$ & $\begin{array}{l}\text { Room air } \\
\text { temp. }\left({ }^{\circ} \mathrm{C}\right)\end{array}$ & $\begin{array}{c}\text { Number } \\
\text { of SC }\end{array}$ & $\begin{array}{l}\text { Number } \\
\text { of EAHE }\end{array}$ \\
\hline \multirow{9}{*}{500} & \multirow{3}{*}{40} & 100 & 3.28 & 29.61 & 5 & 3 \\
\hline & & 500 & 5.16 & 31.13 & 3 & 3 \\
\hline & & 900 & 4.14 & 28.06 & 1 & 1 \\
\hline & \multirow{3}{*}{45} & 100 & 3.01 & 30.92 & 6 & 4 \\
\hline & & 500 & 4.30 & 31.12 & 3 & 4 \\
\hline & & 900 & 4.02 & 31.27 & 2 & 4 \\
\hline & \multirow{3}{*}{50} & 100 & 3.05 & 31.02 & 6 & 6 \\
\hline & & 500 & 3.45 & 31.62 & 3 & 5 \\
\hline & & 900 & 3.06 & 31.52 & 2 & 5 \\
\hline \multirow{9}{*}{1000} & \multirow{3}{*}{40} & 100 & 4.98 & 30.51 & 8 & 6 \\
\hline & & 500 & 4.10 & 31.95 & 2 & 2 \\
\hline & & 900 & 3.63 & 30.69 & 2 & 4 \\
\hline & \multirow{3}{*}{45} & 100 & 4.15 & 30.00 & 8 & 6 \\
\hline & & 500 & 3.27 & 31.15 & 3 & 5 \\
\hline & & 900 & 3.00 & 30.90 & 2 & 5 \\
\hline & \multirow{3}{*}{50} & 100 & 4.18 & 31.95 & 8 & 7 \\
\hline & & 500 & 3.05 & 31.98 & 3 & 6 \\
\hline & & 900 & 3.15 & 31.53 & 3 & 12 \\
\hline \multirow{9}{*}{1500} & \multirow{3}{*}{40} & 100 & 5.20 & 31.36 & 8 & 4 \\
\hline & & 500 & 3.29 & 30.61 & 3 & 5 \\
\hline & & 900 & 3.00 & 30.35 & 2 & 5 \\
\hline & \multirow{3}{*}{45} & 100 & 3.95 & 31.00 & 9 & 9 \\
\hline & & 500 & 3.62 & 31.70 & 4 & 9 \\
\hline & & 900 & 3.17 & 31.60 & 3 & 12 \\
\hline & & 100 & \multirow{3}{*}{\multicolumn{4}{|c|}{ Thermal comfort cannot be provided. }} \\
\hline & 50 & 500 & & & & \\
\hline & & 900 & & & & \\
\hline
\end{tabular}

\subsection{Effects of environmental conditions on the performance of SC-EAHE system}

In the present study, the environmental conditions are referred to as solar radiation and outdoor ambient temperature. Table 4 shows the summary of results pertinent to theoretical calculations for different environmental conditions related to SC-EAHE system. The 
buoyancy driving force increases directly with increment of solar intensity and it causes higher ACH. Thus, less number of SCs are required to drive the cool and heavy air through the EAHEs and to compensate the pressure drops. The results of calculations also show that the required number of EAHEs should be increased to retain the thermal comfort condition when the number of $\mathrm{ACH}$ and indoor air temperature are increased at high solar radiation. The effect of ambient air temperature on stack effect of SC is vice versa. The stack effect decreases when the ambient outdoor temperature rises. Under these conditions, more number of SCs will be required to suitably ventilate the room. The results show that the system can provide the required indoor temperature and $\mathrm{ACH}$ number even at harsh environmental conditions i.e. high temperature of $45^{\circ} \mathrm{C}$ and low solar radiation of $100 \mathrm{~W} / \mathrm{m}^{2}$. If the temperature is higher than $45^{\circ} \mathrm{C}$, the SC won't be able to provide the stack effect and the use of a small fan can help the cool air to flow from EAHE into the room in order to provide thermal comfort conditions.

\section{Conclusions}

In this paper using two solar systems (SC-EAHE and SC-ECC) to meet the cooling load of buildings and thermal needs of inhabitants were compared. The numerical experiments showed that, although the performance strongly depends on the indoor air heat gain and ambient air conditions; the SC-ECC system can prepare good indoor thermal conditions when both cooling demand of the room and the relative humidity of ambient air are low. It was also revealed that, this system can provide thermal comfort conditions even during the night with zero solar radiation. The results about SC-EAHE system show that when both the ambient temperature and cooling demand are high, proper configurations could provide good indoor condition even at poor solar intensity and high ambient air temperature. It should be noted that proper insulation is useful for reducing the number of required SCs and buried pipes and consequently the total initial cost. Comparative survey shows that the SC-EAHE system is the best choice for buildings with poor insulation, but SC-ECC system is better for well insulated building, especially in dry and arid climates and also for low cost night ventilation.

\section{References}

[1] Z. Giabaklou, JA. Ballinger, A passive evaporative cooling system by natural ventilation, Building and Environment 31(6), 1996, pp. 503-507.

[2] M. Manzan, O. Saro, Numerical analysis of heat and mass transfer in passive building component cooled by water evaporation, Energy and Building 34, 2002, 369-375.

[3] YJ. Dai, K. Sumathy, RZ. Wang, YG. Li, Enhancement of natural ventilation in a solar house with a solar chimney and adsorption cooling cavity, Solar Energy 74, 2003, pp. 6575.

[4] S. Chungloo, B. Limmeechokchai, Application of passive cooling system in the hot and humid climate: the case study of solar chimney and wetted roof in Thailand, Building and Environment 42, 2007, pp. 3341-3351.

[5] M. Maerefat, AP. Haghighi, Natural cooling of stand-alone houses using solar chimney and evaporative cooling cavity, Renewable Energy 35, 2010, pp. 2040-2052.

[6] M. Maerefat, AP. Haghighi, Passive cooling of building by using integrated earth to air heat exchanger and solar chimney, Renewable Energy 35, 2010, pp. 2316-2324.

[7] GS. Brager, RJ. De dear, A standard for natural ventilation, ASHRAE Journal 42(10), 2000, pp. 21-28. 